\title{
Effect of microstructure on the electrochemical behavior of Pt/YSZ electrodes
}

\author{
A. Jaccoud ${ }^{\mathrm{a}}$, G. Fóti ${ }^{\mathrm{a}, *}$, R. Wüthrich ${ }^{\mathrm{b}}$, H. Jotterand ${ }^{\mathrm{c}}$, and Ch. Comninellis ${ }^{\mathrm{a}}$ \\ ${ }^{a}$ Institute of Chemical Sciences and Engineering, Ecole Polytechnique Fédérale de Lausanne, CH-1015 Lausanne, Switzerland \\ ${ }^{\mathrm{b}}$ Institute of Manufacturing Systems and Robotics, Ecole Polytechnique Fédérale de Lausanne, CH-1015 Lausanne, Switzerland \\ ${ }^{\mathrm{c} I n s t i t u t e}$ of Physics of the Complex Matter, Ecole Polytechnique Fédérale de Lausanne, CH-1015 Lausanne, Switzerland
}

\begin{abstract}
Two types of $\mathrm{O}_{2}, \mathrm{Pt} / \mathrm{YSZ}$ electrode preparation ( $\mathrm{Pt} / \mathrm{YSZ}$ cermet and sputtered platinum film) have been characterized by SEM and by cyclic voltammetry and chronoamperometry at $450{ }^{\circ} \mathrm{C}$ in $20 \mathrm{kPa}$ oxygen. Cyclic voltammetry on the cermet and on the as-sputtered non-porous film electrode evidenced the characteristics of the $\mathrm{PtO}_{x} / \mathrm{Pt}$ couple. The corresponding redox reaction occurs at the metal/electrolyte interface and it manifests itself by an anodic wave and one of more cathodic peaks in the voltammogram. Heat treatment of the sputtered electrode at $700{ }^{\circ} \mathrm{C}$ in oxygen atmosphere resulted in a porous structure by coalescence of the film. Cyclic voltammetry of the porous film electrode featured the characteristics of the $\mathrm{O}_{2} / \mathrm{O}^{2-}$ couple, i.e. the redox reaction of gaseous oxygen occurring at the tpb. Chronoamperometry at anodic potentials showed similar features for both electrode preparations: an initial inhibition, a current peak and a slow activation, the latter being related to the phenomenon of electrochemical promotion of catalysis.
\end{abstract}

KEY WORDS: Pt/YSZ cermet electrode; Pt film electrode; microstructure; cyclic voltammetry; chronoamperometry.

\section{Introduction}

Electrochemical cells using solid electrolytes such as yttria stabilized zirconia (YSZ) are commonly used for numerous applications. These include gas sensors [1], gas pumps [2], solid oxide fuel cells [3], electrolysis [4] and electrochemically promoted catalysts [5]. YSZ is the most widely studied and employed solid electrolyte. This material conducts at temperatures above $300{ }^{\circ} \mathrm{C}$ via $\mathrm{O}^{2-}$ diffusion. Out of a variety of metals and composite materials employed as electrode, platinum has always been of particular interest due to its electrocatalytic properties. In fact, the $\mathrm{Pt} / \mathrm{YSZ}$ system is the most widely studied example of catalyst electrodes deposited on YSZ [6-14]. Nevertheless, numerous aspects of the electrochemical reactions occurring in an $\mathrm{O}_{2(\mathrm{~g})}, \mathrm{Pt} / \mathrm{YSZ}$ system are still under discussion due to the complexity of the system.

Reproducibility problems are often encountered with the $\mathrm{Pt} / \mathrm{YSZ}$ system. The preparation dependence has been discussed or mentioned in papers dealing with electrochemical promotion of catalysis [15], cyclic voltammetry [16-19], determination of the rate limiting step through impedance measurements [20,21] and chronoamperometry (present paper). Although the general chemical composition of the electrode components is identical, the preparation method can have a great influence on the results. It is explained by the fact that the microstructure has an important impact on the electrode behavior and it is usually highly affected by the preparation.

\footnotetext{
* To whom correspondence should be addressed.

E-mail: gyorgy.foti@epfl.ch
}

In the $\mathrm{O}_{2(\mathrm{~g})}, \mathrm{Pt} / \mathrm{YSZ}$ system, various interfaces exist where electrochemical reactions may take place: three binary interfaces $\left(\mathrm{Pt} / \mathrm{YSZ}, \mathrm{YSZ} / \mathrm{O}_{2(\mathrm{~g})}\right.$ and $\left.\mathrm{Pt} / \mathrm{O}_{2(\mathrm{~g})}\right)$ and the triple phase boundary (tpb) where the three binary interfaces meet. The electrochemical couples playing a role in the overall charge transfer reaction are $\mathrm{PtO}_{x} / \mathrm{Pt}$ and $\mathrm{O}_{2(\mathrm{~g})} / \mathrm{O}^{2-}$. The $\mathrm{PtO}_{x} / \mathrm{Pt}$ couple corresponds to the redox reaction (1) [16-18,22]:

$$
\mathrm{Pt}+\mathrm{xO}^{2-} \leftrightarrows \mathrm{PtO}_{x}+2 \mathrm{xe}^{-}
$$

where use of the symbol $\mathrm{PtO}_{x}$ is due to the ill-defined stoichiometry of the electrochemically formed oxide [23]. This reaction involves reactants from the metal and the electrolyte phases but no reactant from the gaseous phase; consequently it may take place along the metal/ electrolyte interface. It may also occur at the tpb and even at the metal/gas interface via discharge of spillover $\mathrm{O}^{2-}$.

The other electrochemical reaction, involving the couple $\mathrm{O}_{2(\mathrm{~g})} / \mathrm{O}^{2-}$, consists of electron exchange between gaseous oxygen and $\mathrm{O}^{2-}$ ion of the solid electrolyte:

$$
\mathrm{O}^{2-} \leftrightarrows 1 / 2 \mathrm{O}_{2}+2 \mathrm{e}^{-}
$$

This reaction involves reactant from all three phases; therefore it can only take place in the vicinity of the tpb when considering that platinum is impermeable for oxygen. It should be emphasized, that the two electrochemical reactions are not independent of each other, and the first may strongly influence the second. For instance, it is well established that the presence of an oxide film at the metal/electrolyte interface affects the mechanism and kinetics of various anodic processes by changing the electronic properties of the metal surface 
and by imposing a barrier to charge transfer across the surface oxide film $[24,25]$.

The Pt/YSZ system can be seen as two competitive electrochemically activated reactions, involving two distinct redox couples. Each reaction occurs on a particular interface. The probable extension of the electrochemical reaction region along other interfaces (metal/ gas [5,11,26,27] or electrolyte/gas [28-31]) makes the above reaction scheme more complicated.

For in situ investigation of the $\mathrm{O}_{2(\mathrm{~g})}, \mathrm{Pt} / \mathrm{YSZ}$ system, electrochemical techniques are well suited, cyclic voltammetry being the most widely used among them. Developed originally for the study of liquid phase electrochemistry, it was used to investigate the behavior of platinum electrode in aqueous $\mathrm{H}_{2} \mathrm{SO}_{4}[25,32,33]$. These studies demonstrated the site exchange rearrangement of the electrochemically produced monolayer of chemisorbed oxygen. The site exchange mechanism is believed to occur with increasing quantity of bound oxygen and with time. It is stimulated by the repulsive oxygenoxygen and platinum-platinum interactions in the chemisorbed layer.

The technique of voltammetry has been adapted also to high temperature solid electrochemistry [16-19,22,34], and several papers dealing with voltammetric characterization of the $\mathrm{O}_{2(\mathrm{~g})}, \mathrm{Pt} / \mathrm{YSZ}$ system have appeared, reporting on two cathodic peaks observed during the negative potential scan. All papers agree that the first peak corresponds to the reduction of a $\mathrm{Pt}-\mathrm{O}$ compound. However, the nature of this species is still subject to controversy. The peak is attributed either to the reduction of oxygen atoms adsorbed at the tpb [19] or to that of a platinum oxide formed at the $\mathrm{Pt} / \mathrm{YSZ}$ interface [16-18,22]. A second, often poorly defined, cathodic peak has also been reported in several papers [16-19]. Again, various interpretations are proposed, involving either back-spillover oxygen [16,19], platinum oxide [19] or a rearranged type of platinum oxide [17]. " $\mathrm{Pt}-\mathrm{O}$ " is used in this paper as a generic term to designate the different species formed by platinum and oxygen.

In a recent work [16] it was found, that different sorts of oxidized species formed under prolonged anodic oxidation are consumed subsequently during a linear cathodic potential scan resulting in three distinct reduction peaks, one of them being fairly reversible while the two others strongly irreversible. Higher oxidation potential and longer time of polarization favor the irreversible processes. The coexistence of three electrochemical processes is explained with the extension of the triple phase boundary. The rapid first process is assumed to be formation of a $\mathrm{PtO}_{x}$ monolayer at the electrode/metal interface, the second process - a much slower, parallel one - is related to the phenomenon of oxygen back-spillover at the metal/gas interface, and the slowest third process - consecutive to the first one - is attributed to progressive metal oxidation extending from the electrode/metal interface toward the bulk of the metal controlled by solid diffusion.

In the present work, cyclic voltammetric and chronoamperometric experiments are used to study the influence of the microstructure on the electrochemical behavior of $\mathrm{Pt} / \mathrm{YSZ}$ electrodes. For that purpose, two electrochemical cells of distinct electrode microstructure have been investigated. The first cell was equipped with cermet type electrodes, featuring a high dispersion of the electronic and ionic conductors. The dispersion of ionic conductor into the electrode allows the geometric extension of the tpb into the volume of the electrode. Ideally, there must be a percolation of both the electronic and the ionic phase. Cermet electrodes are used in applications where a high activity per unit geometrical area is needed, as in gas sensors [35] and solid oxide fuel cells [36]. The other cell was equipped with a sputtered electrode. In opposition to the cermet electrode, the assputtered metal layer was expected to be very compact [37].

\section{Experimental}

Both electrochemical cells studied in this work are three-electrode pellet type, as shown in figure 1. Working and counter electrodes are located in a symmetrical face-to-face arrangement on each side of the pellet, while the reference electrode is located nearby the counter electrode at a distance of $2 \mathrm{~mm}$. This geometry ensures a symmetrical current and potential distribution in the cell [38]. The electrical contacts were made by using gold wires ( $d=0.15 \mathrm{~mm}$, Cendres \& Métaux) glued onto the electrode surfaces with a tiny dot of gold paste (Gwent C70219R4) then fired at $550{ }^{\circ} \mathrm{C}$.

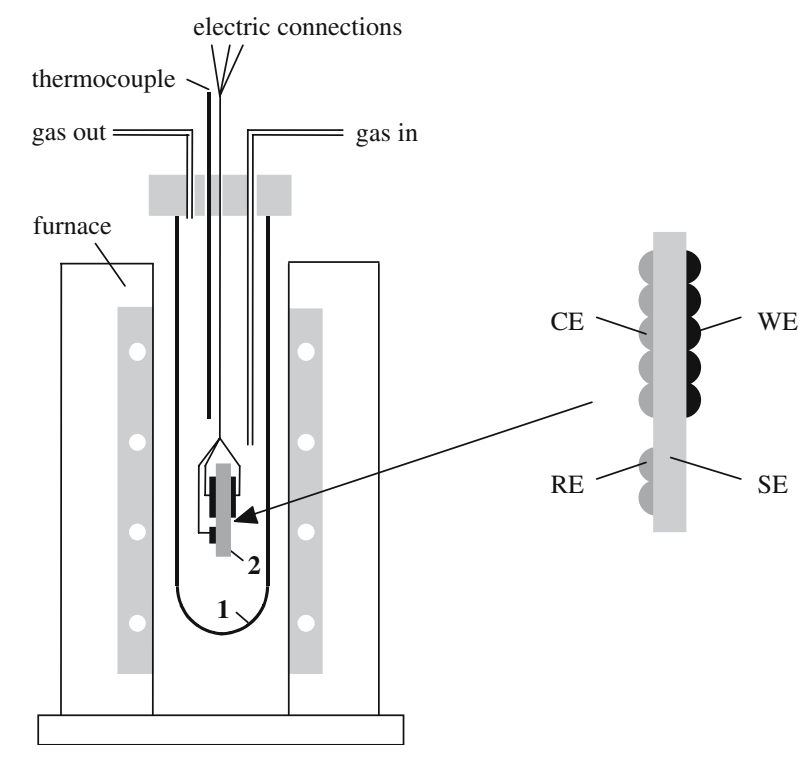

Figure 1. Scheme of the experimental setup. 1: quartz tube; 2: electrochemical cell. WE: working electrode; CE: counter electrode; RE: reference electrode; SE: solid electrolyte (YSZ). 
The Pt/YSZ cermet electrode was prepared by screen printing of a paste composed of $65 \%$ of $1 \mu \mathrm{m}$ particle size platinum powder (Fluka), $11 \%$ of $1 \mu \mathrm{m}$ particle size YSZ $8 \%$ mol powder (Tosoh) and $24 \%$ of a $2 \%$ polyvinyl pyrrolidone solution in isopropanol (Fluka). The paste was screen printed on green $\mathrm{YSZ}\left(8 \mathrm{~mol} \% \mathrm{Y}_{2} \mathrm{O}_{3}\right.$ in $\mathrm{ZrO}_{2}$ ) and sintered at $1400{ }^{\circ} \mathrm{C}$ to give a film thickness of $15 \mu \mathrm{m}$. All three electrodes were deposited according to the same procedure in the shape of $2 \times 4 \mathrm{~mm}$ rectangles. They appeared very stable after sintering. Scanning electron microscopy showed that no apparent morphological changes occurred during a treatment at $700{ }^{\circ} \mathrm{C}$ in a gas mixture of $20 \% \mathrm{O}_{2}$ in $\mathrm{He}$.

The sputtered platinum electrode was deposited onto the YSZ substrate by magnetron sputtering technique in inert atmosphere at room temperature. Direct current (dc) mode was used with a discharge of $330 \mathrm{~V}$ with an argon pressure of $10^{-2}$ mbar. Under these conditions, the deposition rate was $0.09 \mathrm{~nm} \mathrm{~s}^{-1}$ on the YSZ pellet, as determined by profilometric measurement (Alphastep, Model 500) of the film thickness on smooth silicon samples processed simultaneously. A $200 \mathrm{~nm}$ thick Pt electrode was deposited on a $10 \times 15 \times 1 \mathrm{~mm}$ YSZ $8 \%$ mol pellet (Technox 802 , Dynamic Ceramic Ltd). The electrode size is $7 \times 5 \mathrm{~mm}$, hence giving a geometric surface of $0.35 \mathrm{~cm}^{2}$. Platinum counter and reference electrodes have been deposited on the reverse side of the pellet using the same sputtering procedure. Before carrying out the first electrochemical studies, the cell was let in the measuring condition $\left(T=450^{\circ} \mathrm{C}, P_{O_{2}}=20 \mathrm{kPa}\right.$ in $\left.\mathrm{He}\right)$ during two days for stabilization. After having completed a series of voltammetric measurements, a heat treatment has been carried out at $700{ }^{\circ} \mathrm{C}$ in the same atmosphere during $4 \mathrm{~h}$ in order to alter the electrode microstructure, then another series of electrochemical studies were performed as before. SEM images were taken before and after the heat treatment.

The reactor for electrochemical measurements, shown in figure 1, was of single-chamber type where all electrodes were exposed to the same atmosphere. It consisted of a quartz tube of $90 \mathrm{~mL}$ volume closed with a stainless steel cap. The single-pellet three-electrode cell was simply suspended in the reactor with the three gold wires serving as electrical contacts to the electrodes. The temperature in the reactor was measured with a K-type $(\mathrm{NiCr}-\mathrm{Ni})$ thermocouple placed in proximity of the surface of the working electrode. Gold wires and thermocouple were led out the reactor through a four-hole alumina tube (Degussa). The reactor was put into a furnace (XVA271, Horst) equipped with a heat control system (HT30, Horst). Measurements were carried out at $450{ }^{\circ} \mathrm{C}$ under continuous gas flow of $200 \mathrm{~mL} \mathrm{~min}^{-1}$ fed by mass flow controllers (F/201C and E-5514-FA, Bronkhorst). The gas source was a Carbagas certified standard of $\mathrm{O}_{2}(99.95 \%)$ supplied as a $20 \%$ mixture in He $(99.996 \%)$.
The SEM analysis was performed using a JEOL JMS6300-F scanning electron microscope. Electrochemical measurements and data acquisition were made using a scanning potentiostat (Autolab, Model PGSTAT30, Eco Chemie). The potential of the working Pt/YSZ electrode, $E_{\mathrm{wr}}$, is given with respect to the Pt/YSZ reference electrode exposed to constant oxygen partial pressure of $20 \mathrm{kPa}$. Cyclic voltammetry under continuous potential cycling between the two potential limits with different scan rate were performed. Additionally, chronoamperometry at different anodic potentials was carried out.

\section{Results and discussion}

Since the $\mathrm{O}_{2(\mathrm{~g})}, \mathrm{Pt} / \mathrm{YSZ}$ electrochemical reaction scheme presented above consists of two competitive parallel reactions, the measured current corresponds to the added rates of both reactions (1) and (2). In order to split the measured current into these two contributions an approach has been attempted, illustrated in figure 2, using the cermet electrode. In figure 2 curve $a$ corresponds to the steady state current density measured as a function of the applied potential, $E_{\mathrm{wr}}$. The current is considered to be at steady state when no variation with time is observed, reached typically within a few minutes at $450{ }^{\circ} \mathrm{C}$. It is believed to correspond only to the rate of reaction (2), since the steady state rate of reaction (1) is negligible. Therefore, the steady state $i-\mathrm{E}$ curve gives the true rate of reaction (2). However, the electrode might be in a different oxidation state depending on the value of $E_{\mathrm{wr}}$. By subtracting the true tpb current (curve $a$ in figure 2) from the measured cyclic voltammogram (curve $b$ ), one can obtain a residual voltammogram (curve $c$ ) corresponding only to the response of the $\mathrm{Pt} /$ YSZ binary interface, i.e. reaction (1). This voltammogram is very similar to the results found in Pt aqueous voltammetry $[25,32]$. The limited amount of $\mathrm{Pt}-\mathrm{O}$

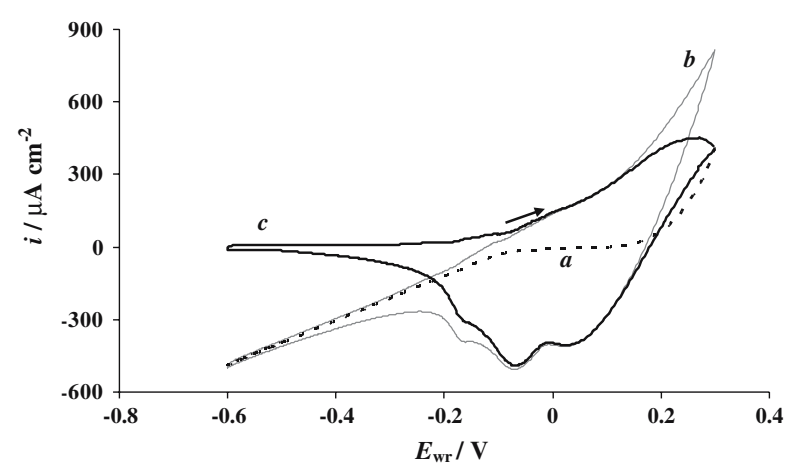

Figure 2. Steady state current density vs. potential behavior (curve $a$ ) and cyclic voltammograms of the cermet electrode. $T=450{ }^{\circ} \mathrm{C}$; $P_{\mathrm{O}_{2}}=20 \mathrm{kPa}$. Curve $b$ : cyclic voltammogram as measured with a scan rate of $5 \mathrm{mV} \mathrm{s}^{-1}$; curve $c$ : residual cyclic voltammogram after subtraction of curve $a$ from curve $b$. Current density is with respect to the geometrical surface area of the electrode. 
species available for reduction, which is formed in the anodic part of the cycling, gives rise to cathodic peaks. Oppositely, the unlimited amount of $\mathrm{O}^{2-}$ available in YSZ creates an anodic wave instead of a peak. However, anodically, there is a limitation due to the passivation of the Pt/YSZ interface by platinum oxides. This is illustrated by the important difference of activity between the cyclic voltammogram and the $i-E$ curve on the anodic part. On the cathodic side, once all $\mathrm{Pt}-\mathrm{O}$ species have been reduced, at $E_{\mathrm{wr}}<-0.3 \mathrm{~V}$, the current of the residual voltammogram drops almost to zero, only the capacitive current due to the double layer charging remains. At these cathodic potentials, the true activity of the reduced $\mathrm{Pt}$ electrode is believed to be measured. However, under high cathodic current, the limiting step may switch from a pure electrochemical to a mixed electrochemical/diffusion regime [20]. These conclusions are of general validity, and they will be used as arguments in the following interpretation of electrochemical analyses.

\subsection{Scanning electron microscopy}

The SEM image of the cermet electrode (figure 3) shows a thick porous electrode composed of linked particles with a large size distribution; bonded particles smaller than $1 \mu \mathrm{m}$ to agglomerates as large as $5 \mu \mathrm{m}$. The metal-like conductivity across the electrode at room temperature confirmed the continuity of the electronic conductor. The sintering at high temperature $\left(1400{ }^{\circ} \mathrm{C}\right)$ created thicker bridges between particles, leading to a very stable microstructure [39]. Based on these observations, the studied cermet electrode was expected to have a high amount of tpb and metal/electrolyte sites per unit geometrical area.

The as-sputtered platinum electrode presents a very compact layer with nearly no porosity (figure 4), as expected for the sputtering deposition technique. The layer follows the topography of the YSZ substrate. Based on the SEM images, a poor population of tpb and a large population of metal/electrolyte sites are expected. As a consequence, the $\mathrm{Pt} / \mathrm{YSZ}$ path described by

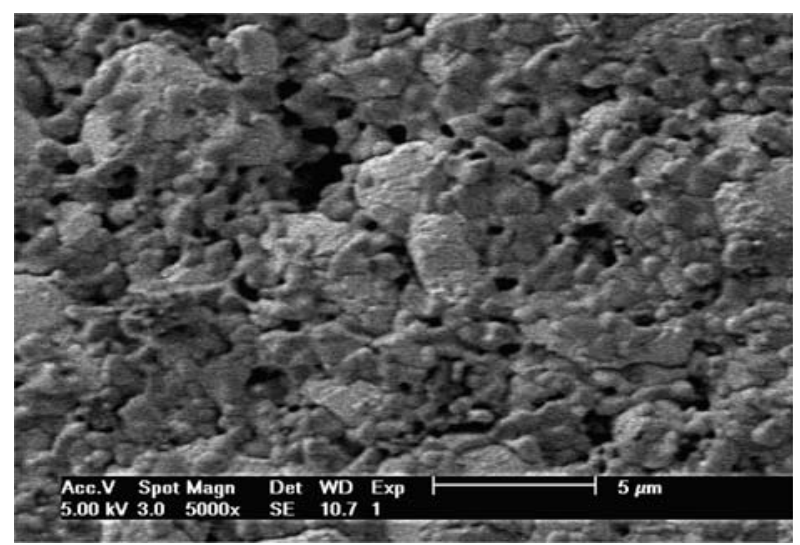

Figure 3. Scanning electron microscopy image of the sintered Pt/YSZ cermet electrode. Enlargement: see scale on the picture.

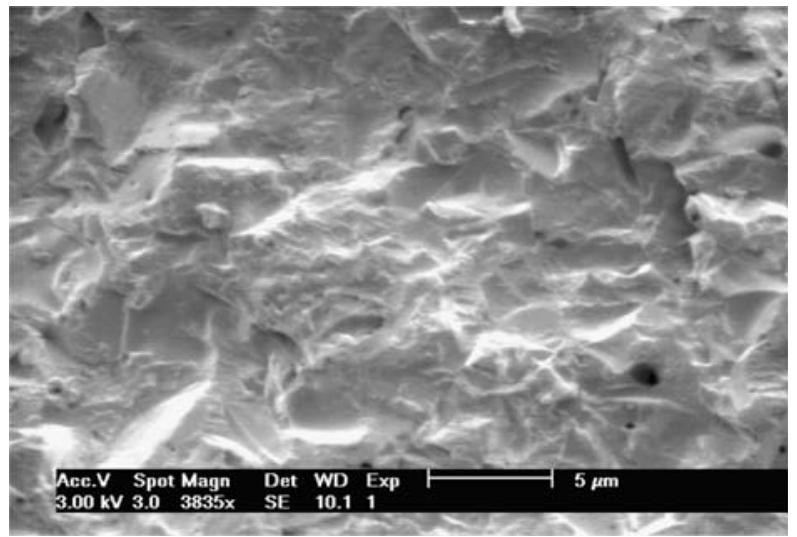

Figure 4. Scanning electron microscopy image of the sputtered $\mathrm{Pt}$ electrode at its as-sputtered state. Enlargement: see scale on the picture.

reaction (1) will be favored over the tpb path of reaction (2).

Figure 5 shows a SEM image of the sputtered electrode after heat treatment at $700{ }^{\circ} \mathrm{C}$ in $20 \mathrm{kPa}$ of $\mathrm{O}_{2}$ for $4 \mathrm{~h}$. The microstructure is composed of a continuous platinum network featuring pores of the size of a few hundred $\mathrm{nm}$ to $1 \mu \mathrm{m}$. The YSZ substrate appears in black through the pores. The heat treatment allowed the formation of agglomerates by a coalescence mechanism [37]. Higher temperature and/or longer time of sintering might resume the coalescence mechanism and break the network, resulting in a non-conductive film formed by isolated agglomerates. Unlike the sputtered electrode before the heat treatment, a higher population of tpb sites and less $\mathrm{Pt} / \mathrm{YSZ}$ sites are expected on the basis of this image, leading to the priority of reaction (2).

\subsection{Cyclic voltammetry}

Figure 6 shows the effect of the cycling scan rate on the voltammograms of the cermet electrode. These voltammograms feature two cathodic peaks and one anodic

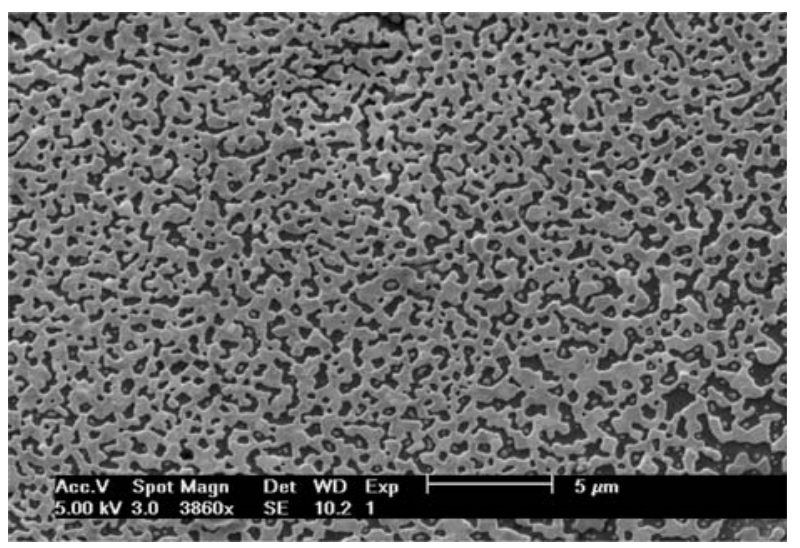

Figure 5. Scanning electron microscopy image of the sputtered $\mathrm{Pt}$ electrode after heat treatment in $P_{\mathrm{O}_{2}}=20 \mathrm{kPa}$ (in He) at $T=700{ }^{\circ} \mathrm{C}$ for $4 \mathrm{~h}$. Enlargement: see scale on the picture. 


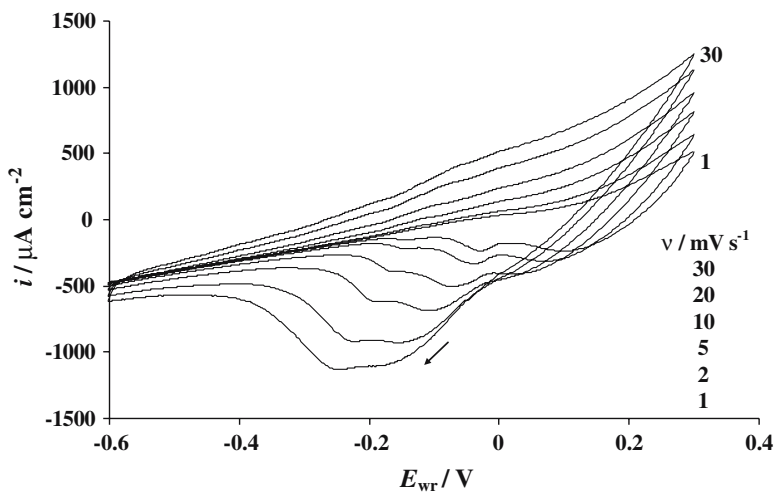

Figure 6. Effect of the scan rate, $v$, on the cyclic voltammogram of the cermet electrode. $T=450{ }^{\circ} \mathrm{C} ; P_{O_{2}}=20 \mathrm{kPa}$. Current density is with respect to the geometrical surface area of the electrode.

wave, as reported in a previous paper [16]. The cathodic peak currents and the anodic current are strongly dependent on the scan rate $v$. In contrast, at high cathodic potentials $\left(E_{\mathrm{wr}}<-0.4 \mathrm{~V}\right)$, the current is almost scan rate independent. The integration of the overall cathodic peak gives values between 5 and $20 \mathrm{PtO}$ monolayers, the monolayer value being $440 \mu \mathrm{C} \mathrm{cm}^{-2}$ [32]. This can have two causes. Firstly, the microstructure effect: the studied electrode is a cermet, therefore the Pt/YSZ interface can exceed the geometric surface by orders of magnitude depending on the quality of the electronic/ionic conductor dispersion. Secondly, the chemical effect: the oxide can grow toward the bulk of the platinum, as proposed in an earlier paper [16]. The oxide growth mechanism may be rearrangement of the oxide layer via place exchange between metal and oxide ions, similar to the mechanism occurring in liquid electrochemistry of platinum $[25,32,33]$.

Figure 7 shows the effect of the scan rate on the shape of the voltammograms of the as-sputtered electrode. These voltammograms feature an anodic wave and a cathodic peak. Similarly to the cermet case, the

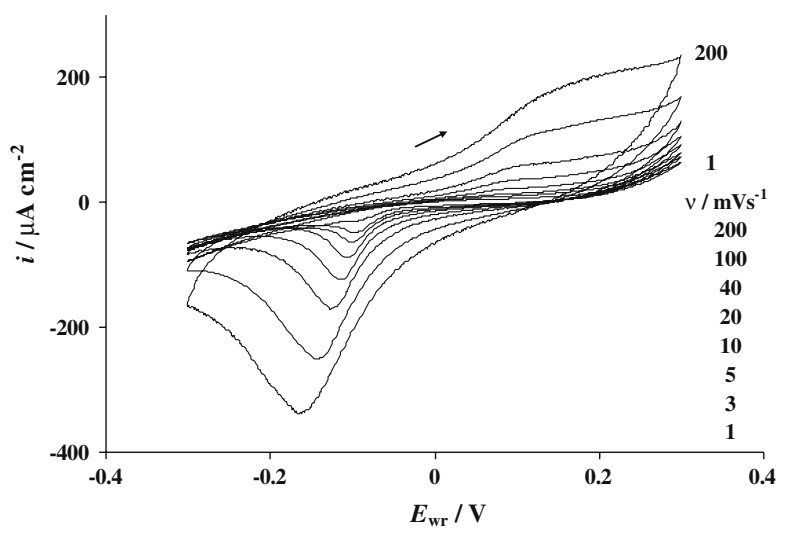

Figure 7. Effect of the scan rate, $v$, on the cyclic voltammogram of the as-sputtered platinum electrode. $T=450{ }^{\circ} \mathrm{C} ; P_{\mathrm{O}_{2}}=20 \mathrm{kPa}$. Current density is with respect to the geometrical surface area of the electrode. voltammogram shape has a high scan rate dependency, indicating a behavior according mostly to reaction (1). The current densities at small scan rates are much lower than for the cermet electrode. This is obviously due to a smaller tpb length per unit geometrical area, as it could be expected from the different electrode dispersions seen on the SEM images. In contrast to the cermet electrode, only one cathodic peak has been observed with this electrode. In literature, the observation of a second peak is uncertain $[16-19,22]$. The presence of a second peak in the cyclic voltammogram depends mainly on the microstructure of the electrode, hence on its history, as found in aqueous electrochemistry [40].

The cathodic peaks seen in figure 7 have been integrated. Figure 8 shows the corresponding charge as a function of the cycling rate in a decimal semi-logarithmic scale. The charge increases as the rate decreases. This tendency was expected given that, at lower rates, more time is conceded to form $\mathrm{Pt}-\mathrm{O}$ species. The value of the charge $Q$ seems to saturate at approximately $400 \mu \mathrm{C} \mathrm{cm}^{-2}$, slightly below the value of a $\mathrm{Pt}-\mathrm{O}$ monolayer. This result tends to confirm the conclusion of the paper written by Kenjo et al. [22], proposing a method to determine the Pt/YSZ surface from the peak charge saturation value. It has been shown [41] that, independently of the oxygen partial pressure and the temperature, chemical oxidation of platinum never exceeds one monolayer of $\mathrm{Pt}-\mathrm{O}$.

Figure 9 shows the scan rate dependency of the cyclic voltammogram of the sputtered electrode after heat treatment at $700^{\circ} \mathrm{C}$ in $20 \mathrm{kPa} \mathrm{O}_{2}$ for $4 \mathrm{~h}$. Unlike the untreated sputtered electrode, almost no cathodic peak is observable, the scan rate dependency is weak and the anodic-cathodic behaviors are almost symmetrical. Moreover, at low scan rate, the treated electrode is over three fold more active than in its as-sputtered state. These cyclic voltammetric results show that the

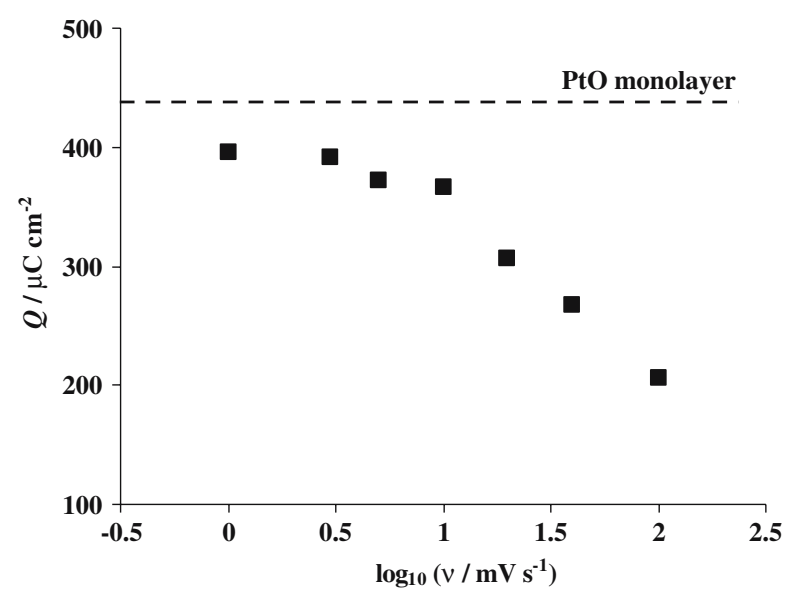

Figure 8. Voltammetric charge density of the as-sputtered platinum electrode, $Q$, obtained by integration of the cathodic peaks of figure 7 , as a function of the decimal logarithm of the scan rate, $v$. Charge density is with respect to the geometrical surface area of the electrode. 


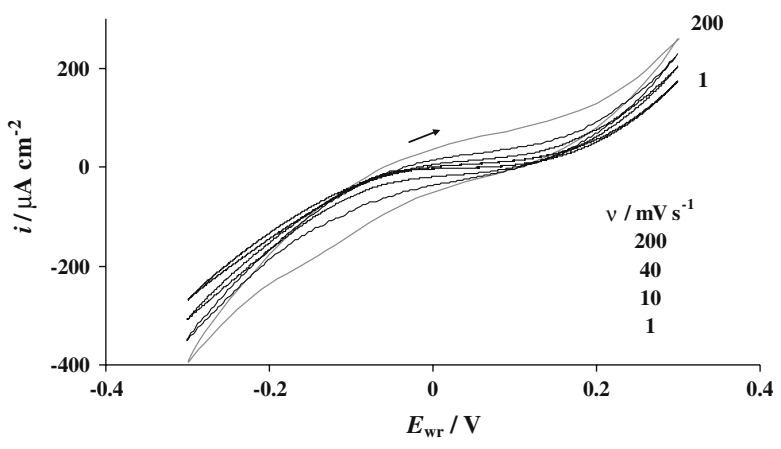

Figure 9. Effect of the scan rate, $v$, on the cyclic voltammogram of the sputtered platinum electrode after heat treatment at $T=700^{\circ} \mathrm{C}$ in $20 \mathrm{kPa}$ of $\mathrm{O}_{2}$ for $4 \mathrm{~h}$. The voltammograms were recorded at $T=450{ }^{\circ} \mathrm{C}$ and $P_{O_{2}}=20 \mathrm{kPa}$. Current density is with respect to the geometrical surface area of the electrode.

electrode behavior has been altered by the heat treatment. Before the treatment, the reaction (1) was defining most of the electrode behavior. The appearance of distinct peaks, the high scan rate dependency and the high apparent capacitance characterized this behavior. After the treatment, the activity of the competing reaction (2) predominates and hinders the current corresponding to reaction (1). This change in behavior can be linked to the morphological changes observed by SEM. The heat treatment caused a coalescence of the platinum layer, decreasing the amount of metal/electrolyte sites and increasing the amount of tpb sites. Comparing the current density values at $E_{\mathrm{wr}}=0.3 \mathrm{~V}$ and $v=1 \mathrm{mV} \mathrm{s}^{-1}$, from figures 6 and 9, the anodic activity is roughly three fold higher for the cermet than for the heat treated sputtered electrode.

The preparation method, hence the microstructure of the electrode, determines whether the electrochemical behavior of the $\mathrm{O}_{2(\mathrm{~g})}, \mathrm{Pt} / \mathrm{YSZ}$ system will tend to have a metal/electrolyte (reaction 1) or a tpb behavior (reaction 2). Cyclic voltammetry appears a useful tool to identify the type of behavior. Based on results from literature and from experiments conducted in our laboratory using various electrode preparations, general trends can be drawn concerning the global behavior. For electrodes prepared using paste [17-19,22], pressed point [18], pressed foil or chloroplatinic acid thermal decomposition [39], the behavior depends on the pretreatment temperature. Higher pretreatment temperature favors the metal/electrolyte (reaction 1) behavior. This is due to the sintering of the porous film or the rough metalelectrolyte contact, leading to an agglomerated, smoother, more compact microstructure [39] and to an extended Pt/YSZ surface [22]. In literature [17,19,22], this effect is usually obtained for treatment at temperatures equal to or above $900{ }^{\circ} \mathrm{C}$. Interestingly, as seen in this paper, non-treated as-sputtered electrodes feature a high Pt/YSZ behavior due to a non porous compact structure and intimate platinum/substrate contact. This is typical for sputter deposition. However, the film tends to coalesce to become porous when treated at intermediate temperature $\left(600-700{ }^{\circ} \mathrm{C}\right)$, leading to a tpb behavior. Further heat treatment might favor the $\mathrm{Pt} /$ YSZ behavior by further sintering. Working at low oxygen partial pressures is another way to favor the $\mathrm{Pt} /$ YSZ behavior with respect to the tpb behavior. Limiting the gaseous oxygen supply to the electrode reduces the rate of reaction (2). Since gaseous oxygen is not directly involved in reaction (1), the latter will be less affected and the resulting voltammograms will mostly features $\mathrm{Pt} / \mathrm{YSZ}$ characteristics, as seen in refs [16,18,22].

\subsection{Chronoamperometry}

Chronoamperometry was used here as a method to complement the cyclic voltammetric data. The intention was to study the evolution of current with time under potentiostatic polarization, instead of a sweeping polarization imposed in cyclic voltammetry. Chronoamperometric measurements were performed on the cermet electrode and on the heat treated sputtered electrode. A pretreatment was performed during $300 \mathrm{~s}$ at $E_{\mathrm{wr}}=-0,6 \mathrm{~V}$ before measuring each curve. It aimed to reduce all residual $\mathrm{Pt}-\mathrm{O}$ species and to reach an identical initial state. After the cathodic pretreatment, the potential was immediately switched to a chosen anodic potential, and the current density was measured as a function of time.

The series of curves in figure 10 shows the effect of the anodic potential $E_{\mathrm{wr}}$ on the chronoamperometric curves obtained with the cermet electrode. The value of the initial current $(t=0 \mathrm{~s})$ increases with $E_{\mathrm{wr}}$. A fast current drop is observed at very short times $(t<10 \mathrm{~s})$. At longer times $(10 \mathrm{~s}<t<100 \mathrm{~s})$ a peak is observed, its size is highly dependent on $E_{\mathrm{wr}}$. At long times $(t>150 \mathrm{~s})$ the current is rather stable, however, a slight increase occurs for high values of $E_{\mathrm{wr}}$.

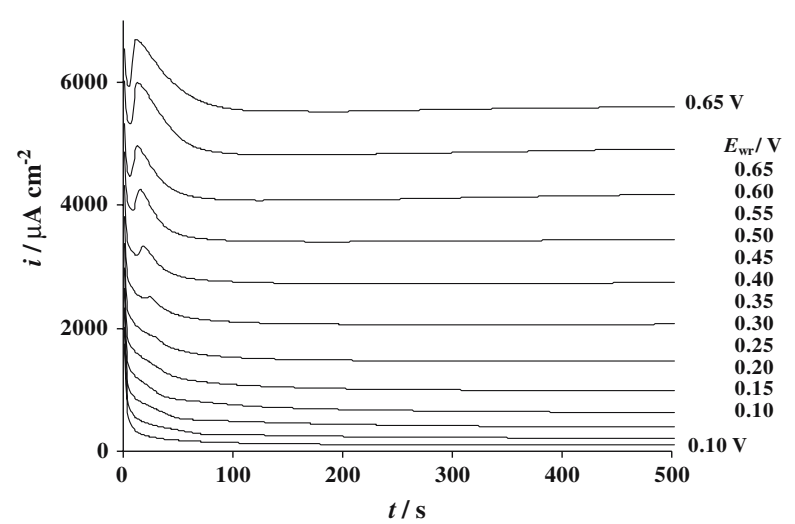

Figure 10. Chronoamperometric recordings at various anodic potentials, $E_{\mathrm{wr}}$, with the cermet electrode. Experimental conditions: $T=450{ }^{\circ} \mathrm{C} ; P_{O_{2}}=20 \mathrm{kPa}$, cathodic pretreatment at $E_{\mathrm{wr}}=-0.6 \mathrm{~V}$ during $300 \mathrm{~s}$. Current density is with respect to the geometrical surface area of the electrode. 
Chronoamperometric curves obtained with the heat treated sputtered electrode are shown in figure 11. Figure 12 shows the same data as figure 11, but the scale focuses on shorter times. Qualitatively, the same features as for the cermet electrode appear on the curves, i.e. a current drop at very short times (better seen in figure 12), a peak at longer times and a current increase at yet longer times. However, the relative importance of each feature and the times at which they appear differ much. The times corresponding to the passivation and to the peak are shorter than for the cermet electrode. Indeed, the passivation and peak features take place at times below $20 \mathrm{~s}$, while $100 \mathrm{~s}$ were necessary with the cermet electrode. The peak size increases with $E_{\mathrm{wr}}$, as reported with the cermet electrode. One distinct feature of the sputtered electrode is the important increase of electrode activity observed at high $E_{\mathrm{wr}}$ values at $t>20 \mathrm{~s}$, whereas this activation is barely apparent on the cermet electrode. As one could expect by comparing cyclic voltammograms from figures 6 and 9 , the current

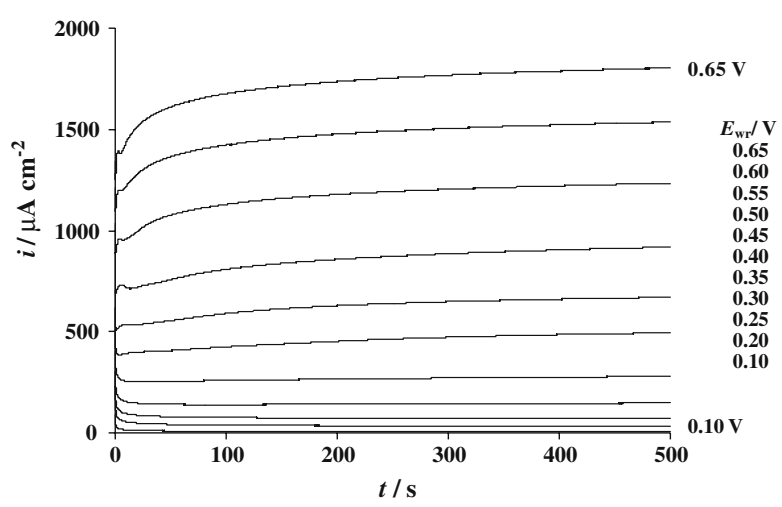

Figure 11. Chronoamperometric recordings at various anodic potentials, $E_{\mathrm{wr}}$, with the sputtered platinum electrode after heat treatment at $T=700{ }^{\circ} \mathrm{C}$ in $20 \mathrm{kPa}$ of $\mathrm{O}_{2}$ for $4 \mathrm{~h}$. Experimental conditions of chronoamperometry as in figure 10 . Current density is with respect to the geometrical surface area of the electrode.

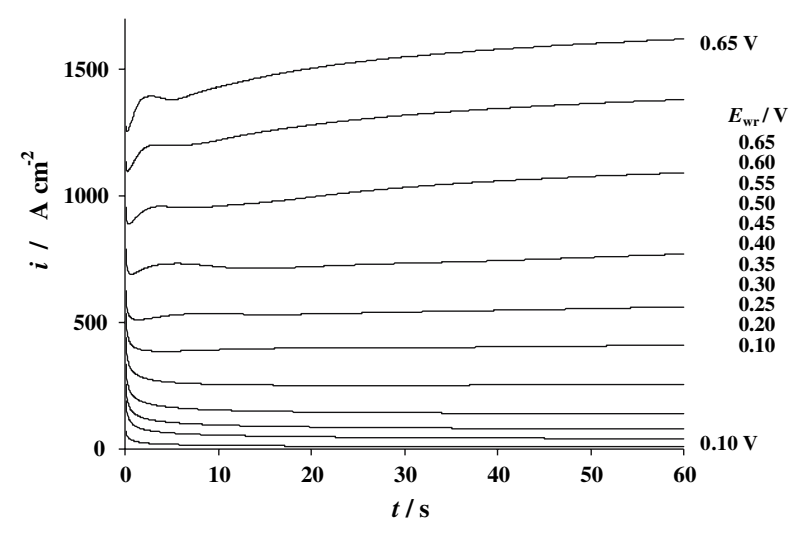

Figure 12. Short time range zoom on the curves of figure 11. density is roughly three fold smaller than with the cermet electrode.

Based on SEM, CV and chronoamperometry results obtained in this work as well as results from literature, a qualitative model is proposed to interpret the reported observations. The measured current at $t=0$ corresponds to the sum of the rates of reactions (1) and (2). Since the cathodic pretreatment reduced all probable platinum oxide, these reactions take place on a metallic surface of platinum. The subsequent anodic polarization has three effects on the electrode. The first effect is inhibiting, the second creates a peak of activity, and the third is activating.

\subsubsection{Inhibition}

The current drop, observed at very small times ( $t<10 \mathrm{~s}$ on the cermet electrode), is probably caused by the passivation of the Pt/YSZ interface via formation of an oxide monolayer due to the auto-inhibiting character of reaction (1). Oxygen containing species may also block the tpb sites [24].

\subsubsection{Current peak}

Subsequent to inhibition and observed with higher $E_{\mathrm{wr}}$ values, it may be due to the $\mathrm{Pt}-\mathrm{O}$ site exchange taking place at the Pt/YSZ binary interface. Such rearrangement is observed in Pt aqueous electrochemistry $[25,33,42]$ when the anodic polarization exceeds a critical value. A similar rearrangement mechanism could be valid as well at the Pt/YSZ interface, as mentioned in ref [17]. In order to imagine a possible mechanism, one may speculate in the following way. The driving force of the site-exchange mechanism is the charge repulsion between the atoms forming the $\mathrm{Pt}-\mathrm{O}$ monolayer. When the oxygen coverage reaches a given value, the rearrangement starts. It creates a population of a more stable $\mathrm{Pt}-\mathrm{O}$ species, leading to a surface state with a lower energy. When the site exchange takes place, the displaced platinum atom becomes in contact with the YSZ surface. An oxygen atom coming from the YSZ can adsorb on this new interfacial platinum atom. The current corresponding to the oxidation of the rearranged platinum is added to the current from reactions (1) and (2). As the rearrangement takes places, the platinum oxide layer thickens and the interface becomes more resistant to charge transfer. This causes a decrease of the site exchange related current. The onset of the rearrangement mechanism followed by its self inhibition may lead to the measured current peak in the chronoamperometry measurements. At low $E_{\mathrm{wr}}$ values, the oxygen coverage might not be sufficient to start the site exchange mechanism, explaining the disappearance of the peak at these potential values. The peak is much more apparent in the measurements made with the cermet electrode than with the heat treated sputtered electrode. This is consistent with the fact that the cermet electrode has a higher Pt/YSZ behavior. 


\subsubsection{Activation}

The current increase, appearing after the peak, is an effect of long relaxation time caused by the imposed positive polarization. The amplitude of the activation depends highly on $E_{\mathrm{wr}}$. In literature, the Pt/YSZ electrode activation by a high anodic current is explained in two different ways. Most papers assume a current induced morphological change, increasing the tpb [35,39,43-47], hence the rate of reaction (2), while others propose an extension of the electrochemical reaction site toward the YSZ/gas interface by non negligible electronic conduction in YSZ [31,48]. The changes in microstructure could be caused by a surface breakdown phenomenon due to the large electric field, as observed in liquid electrochemistry [49] or by sublimation of the electrochemically formed platinum oxide [50]. The activation can also be caused by the weakening of strongly bonded oxygen atoms which are blocking the tpb reaction zone. The weakening of the $\mathrm{Pt}-\mathrm{O}$ bound would be initiated by the presence of spillover species [5].

The cermet electrode has been sintered at high temperature $\left(1400{ }^{\circ} \mathrm{C}\right)$ which makes it morphologically very stable. On the contrary, the sputtered electrode has been heat treated at a lower temperature $\left(700^{\circ} \mathrm{C}\right)$. SEM images showed that it features smaller, finer pores and bridges, hence a less stable microstructure. This could explain the higher amplitude of the activation on the sputtered electrode with respect to the cermet electrode.

\section{Conclusion}

In this work, the link between Pt/YSZ electrode preparation, the consequent microstructure and voltammetric measurements in $\mathrm{O}_{2}$ containing atmosphere is discussed. It has been shown that microstructure has a spectacular effect on cyclic voltammetry. The major outcomes are summarized as follow:

- Typical $\mathrm{O}_{2}, \mathrm{Pt} / \mathrm{YSZ}$ characteristics such as cathodic peaks and the anodic wave are distinctly observed with cermet electrodes calcinated at very high temperature and non-porous as-sputtered electrodes.

- The charge obtained by integration of the cathodic peak in the cyclic voltammogram of non-porous assputtered electrodes tends to the value of a monolayer of $\mathrm{Pt}-\mathrm{O}$.

- Cyclic voltammetry on sputtered electrodes rendered highly porous by temperature treatment features only weak $\mathrm{O}_{2}, \mathrm{Pt} / \mathrm{YSZ}$ characteristics. Instead, the reaction of the $\mathrm{O}_{2} / \mathrm{O}^{2-}$ redox couple at the three phase boundary clearly predominates.

\section{Acknowledgment}

Financial supports from the Fonds National Suisse de la Recherche Scientifique is gratefully acknowledged.

\section{References}

[1] L.R. Skubal and M.C. Vogt, Proc.SPIE - Int. Soc. Optical Eng. 5586 (2004) 45.

[2] T. Hibino, Y. Kuwahara, T. Otsuka, N. Ishida and T. Oshima, Solid State Ionics 107 (1998) 217.

[3] V. Kordesch and J.C.T. De Olivera, in: Ullmann's Encyclopedia of Industrial Chemistry, Vol. A12, (Wiley, New York, 1989) Fuel Cells.

[4] G. Tao, K.R. Sridhar and C.L. Chan, Solid State Ionics 175 (2004) 615.

[5] C.G. Vayenas, S. Bebelis, C. Pliangos, S. Brosda and D. Tsiplakides, Electrochemical Activation of Catalysis: Promotion, Electrochemical Promotion, and Metal-Support Interactions (Kluwer Academic/Plenum Publishers, New York, 2001).

[6] M.J. Verkerk, B.J. Middelhuis and A.J. Burggraaf, Solid State Ionics 6 (1982) 159.

[7] J. Sasaki, J. Mizusaki, S. Yamauchi and K. Fueki, Solid State Ionics 3-4 (1981) 531.

[8] J. Mizusaki, K. Amano, S. Yamauchi and K. Fueki, Solid State Ionics 22 (1987) 313.

[9] J. Mizusaki, K. Amano, S. Yamauchi and K. Fueki, Solid State Ionics 22 (1987) 323.

[10] A. Mitterdorfer and L.J. Gauckler, Solid State Ionics 120 (1999) 211.

[11] A. Mitterdorfer and L.J. Gauckler, Solid State Ionics 117 (1999) 187.

[12] B. Luerssen, J. Janek and R. Imbihl, Solid State Ionics 141-142 (2001) 701.

[13] M. Goge, K. Heggestad and M. Gouet, Solid State Ionics 18-19 (1986) 1228

[14] K. Schindler, D. Schmeisser, U. Vohrer, H.D. Wiemhofer and W. Gopel, Sens. Actuators 17 (1989) 555.

[15] J. Poppe, S. Völkening, A. Schaak, J. Janek and R. Imbihl, Phys. Chem. Chem. Phys. 1 (2000) 5241.

[16] A. Jaccoud, G. Fóti and Ch. Comninellis, Electrochim. Acta, 51 (2006) 1264.

[17] Tsaofang Chao, K.J. Walsh and P.S. Fedkiw, Solid State Ionics 47 (1991) 277.

[18] M.W. Breiter, K. Leeb and G. Fafilek, J. Electroanal. Chem. 434 (1997) 129.

[19] J. Yi, A. Kaloyannis and C.G. Vayenas, Electrochim. Acta 38 (1993) 2533.

[20] S.P. Yoon, S.W. Nam, S.-G. Kim, S.-A. Hong and S.-H. Hyun, J. Power Sour. 115 (2003) 27.

[21] S.P. Yoon, S.W. Nam, J. Han, T.-H. Lim, S.-A. Hong and S.-H. Hyun, Solid State Ionics 166 (2004) 1.

[22] T. Kenjo, Y. Yamakoshi and K. Wada, J. Electrochem. Soc. 140 (1993) 2151

[23] R.J. Berry, Surf. Sci. 76 (1978) 415

[24] S. Sridhar, V. Stancovski and U. Pal, Solid State Ionics 100 (1997) 17.

[25] G. Jerkiewicz, G. Vatankhah, J. Lessard, M.P. Soriaga Y.-S. Park, Electrochim. Acta 49 (2004) 1451.

[26] J. Fleig and J. Jamnik, J. Electrochem. Soc. 152 (2005) E138.

[27] C.G. Vayenas and G.E. Pitselis, Ind. Eng. Chem. 40 (2001) 4209.

[28] E. Siebert, Electrochim. Acta 39 (1994) 1621.

[29] S.N. Shkerin, S. Gormsen and M. Mogensen, Russ. J. Electrochem. 40 (2004) 136.

[30] S.N. Shkerin, S. Gormsen, S. Primdahl and M. Mogensen, Russ. J. Electrochem. 39 (2003) 1058.

[31] E.J.L. Schouler and M. Kleitz, J. Electrochem. Soc. 134 (1987) 1045.

[32] H. Angerstein-Kozlowska, B.E. Conway and W.B.A. Sharp, J. Electroanal. Chem. 43 (1973) 9.

[33] K.J. Vetter and J.W. Schultze, J. Electroanal. Chem. 34 (1972) 131.

[34] P.A. van Manen, R. Weewer and H.W. de Wit, J. Electrochem. Soc. 139 (1992) 1130. 
[35] Takao Murase and T. Yoshimura, Pat. Nr. 5130002, Method of processing oxygen concentration sensor by applying AC current, and the thus processed sensor, 1992.

[36] A. Barbucci, R. Bozzo, G. Cerisola and P. Costamagna, Electrochim. Acta 47 (2002) 2183.

[37] B. El Roustom, G. Fóti and Ch. Comninellis, Electrochem. Comm. 7 (2005) 398.

[38] G. Fóti, V. Stankovic, I. Bolzonella and Ch. Comninellis, J. Electroanal. Chem. 532 (2002) 191.

[39] S. Pizzini, M. Bianchi, P. Colombo and S. Torchio, J. Appl. Electrochem. 3 (1973) 153.

[40] L.D. Burke and M.B.C. Roche, J. Electroanal. Chem. 137 (1982) 175.

[41] R.W. McCabe, C. Wong and H.S. Woo, J. Catal. 114 (1988) 354
[42] H. Angerstein-Kozlowska and B.E. Conway, J. Electroanal. Chem. 95 (1979) 1.

[43] L. Bay and T. Jacobsen, Solid State Ionics 93 (1997) 201.

[44] T. Jacobsen and L. Bay, Electrochim. Acta 47 (2002) 2177.

[45] T. Jacobsen, B. Zachau-Christiansen, L. Bay and M. Juhl Jorgensen, Electrochim. Acta 46 (2001) 1019.

[46] S.V. Karpachev and Y.M. Ovchinnikov, Russ. J. Electrochem. 5 (1969) 200.

[47] J.E. Bauerle, J. Phys. Chem. Solids 30 (1969) 2657.

[48] S.N. Shkerin, Russ. J. Electrochem. 40 (2004) 510.

[49] V. Zwilling, M. Aucouturier and E. Darque-Ceretti, Electrochim. Acta 45 (1999) 921.

[50] C.-P. Hwang and C.-T. Yeh, J. Catal. 182 (1999) 48. 